\section{Light-Scattering Characterization of Fullerene-Containing Poly(alkyl methacrylate)s in THF}

\section{Xiaohui Wang, ${ }^{\dagger}$ S. H. Goh, ${ }^{\ddagger}$ Z. H. Lu, † S. Y. Lee, ${ }^{\ddagger}$ and Chi Wu,t,\$}

Department of Chemistry, The Chinese University of Hong Kong, Shatin, New Territories, Hong Kong; Department of Chemistry, National University of Singapore,

Singapore 119260, Republic of Singapore; and The Open Laboratory of Bond Selective Chemistry, Department of Chemical Physics, University of Science and Technology of China, HeFei, China

Received November 16, 1998

Revised Manuscript Received February 4, 1999

\section{Introduction}

Fullerene $\left(\mathrm{C}_{60}\right)$ has attracted much attention due to its unique chemical and physical properties. ${ }^{1}$ However, many of its potential applications have been hindered by its poor solubility and processability. Grafting polymer chains on fullerene are particularly interesting because a combination of fullerene and polymer not only significantly improves the solubility and processability of fullerene but also directly leads to useful materials. This is why various kinds of $\mathrm{C}_{60}$-containing polymers have been synthesized, but their solution behaviors have not been carefully studied. ${ }^{2-4}$ Recently, a static laser light-scattering study showed that fullerenes grafted with two well-defined polystyrene or poly(p-vinylphenol) arms could form micelle in tetrahydrofuran (THF), 5 contrary to the expectation of molecularly dispersed fullerene solution. Moreover, Lu et al. ${ }^{6}$ showed that narrowly distributed fullerene-containing poly(alkyl methacrylate)s could be prepared, which provides a basis for the study of their solution properties. In this study, we intend to study two fullerene-containing polymers by a combination of static and dynamic laser light scattering (LLS) in order to confirm whether and under which condition they are able to form multimolecular micelle-like aggregates in solution.

\section{Experimental Section}

Sample Preparation. Tetrahydrofuran (THF) (Aldrich) and benzene (Aldrich) were used without further purification. $\mathrm{C}_{60}$-containing poly(methyl methacrylate) and poly(n-butyl methacrylate) are respectively denoted as $A M 50 F$ and $A B 50 F$ thereafter. The preparations of $\mathrm{AM} 50 \mathrm{~F}$ and $\mathrm{AB} 50 \mathrm{~F}$ were detailed elsewhere. ${ }^{6}$ The concentrations of their THF or benzene solutions were in the range $9.04 \times 10^{-4}-5.32 \times 10^{-3}$ $\mathrm{g} / \mathrm{mL}$. The solutions were clarified with a $0.2 \mu \mathrm{m}$ Millipore PTFE filter to remove dust.

Laser Light Scattering. A modified commercial lightscattering spectrometer (ALV/SP-125) equipped with an ALV5000 multi- $\tau$ digital time correlator and a $\mathrm{He}-\mathrm{Ne}$ laser (model 127; output power $=40 \mathrm{~mW}$ at $\lambda=632 \mathrm{~nm}$ ) was used. The primary beam is vertically polarized with respect to the scattering plane. The details of the LLS instrumentation and theory can be found elsewhere. 7,8 All the LLS measurements were carried out at $25 \pm 0.1{ }^{\circ} \mathrm{C}$.

In static LLS, the angular dependence of the excess absolute time-averaged scattering light intensity, known as the excess

† The Chinese University of Hong Kong.

₹ National University of Singapore.

$\S$ University of Science and Technology of China.

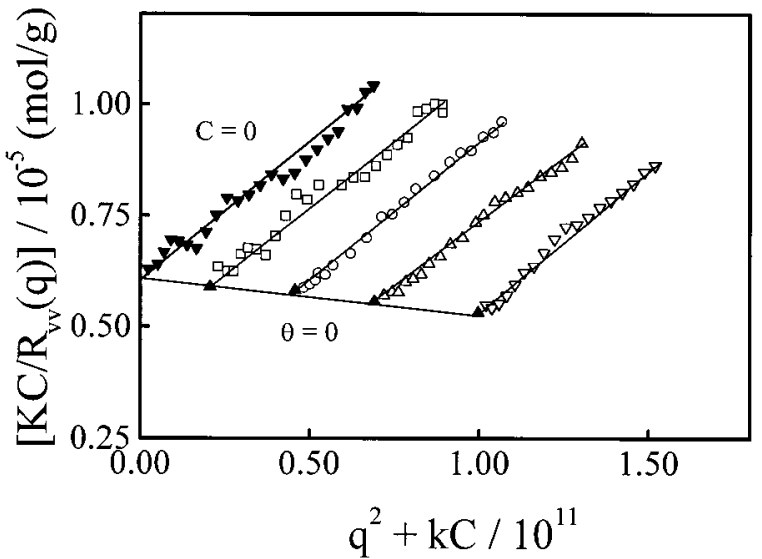

Figure 1. Typical Zimm plot of fullerene-containing poly(methyl methacrylate) (AM 50F) in THF, where $\mathrm{T}=25^{\circ} \mathrm{C}$ and the polymer concentration ranged from $9.04 \times 10^{-4}$ to $5.32 \times$ $10^{-3} \mathrm{~g} / \mathrm{mL}$.

Rayleigh ratio $R_{v v}(q)$, of dilute polymer solutions was measured. $R_{v v}(q)$ is related to the weight-average molar mass $\left(M_{w}\right)$, polymer concentration $(C)$, and the scattering angle $(\theta)$ as $^{9}$

$$
\frac{\mathrm{KC}}{\mathrm{R}_{\mathrm{v}}(\mathrm{q})} \approx \frac{1}{\mathrm{M}_{\mathrm{w}}}\left(1+\frac{1}{3}\left\langle\mathrm{R}_{\mathrm{g}}{ }^{2}\right\rangle_{\mathrm{z}} \mathrm{q}^{2}\right)+2 \mathrm{~A}_{2} \mathrm{C}
$$

where $K=4 \pi^{2} n^{2}(d n / d C)^{2} /\left(N_{A} \lambda_{0}{ }^{4}\right)$ and $q=\left(4 \pi n / \lambda_{0}\right) \sin (\theta / 2)$ with $\mathrm{N}_{\mathrm{A}}, \mathrm{dn} / \mathrm{dC}, \mathrm{n}$, and $\lambda_{0}$ being the Avogadro number, the specific refractive index increment, the solvent refractive index, and the wavelength of the light in vacuo, respectively; $A_{2}$ is the second virial coefficient; and $\left\langle\mathrm{R}_{\mathrm{g}}{ }^{2}\right\rangle_{z}{ }^{1 / 2}$ (or written as $\left\langle\mathrm{R}_{\mathrm{g}}\right\rangle$ ) is the root-mean square $z$-average radius of gyration of the polymer chain in solution. For AM50F and AB50F in THF at T $=25$ ${ }^{\circ} \mathrm{C}$ and $\lambda=632 \mathrm{~nm}$, the respective values of $\mathrm{dn} / \mathrm{dC}=0.095$ and $0.083 \mathrm{~mL} / \mathrm{g}$ were determined by using a novel and highprecision differential refractometer. ${ }^{10}$ In dynamic LLS, the intensity-intensity time correlation function $\mathrm{G}^{(2)}(\mathrm{t}, \mathrm{q})$ in the self-beating mode was measured. The Laplace inversion of $\mathrm{G}^{(2)}$ $(\mathrm{t}, \mathrm{q})$ can lead to a line-width distribution $\mathrm{G}(\Gamma),{ }^{7,8,11}$ which can be further converted to a translational diffusive coefficient distribution $\mathrm{G}(\mathrm{D})$ by $\Gamma=\mathrm{Dq}^{2}$ and a hydrodynamic radius distribution by the Stokes-Einstein equation: $\mathrm{R}_{\mathrm{h}}=\mathrm{k}_{\mathrm{B}} \mathrm{T} / 6 \pi \eta \mathrm{D}$, where $\eta, \mathrm{k}_{\mathrm{B}}$, and $\mathrm{T}$ are the solvent viscosity, the Boltzmann constant, and the absol ute temperature, respectively.

\section{Results and Discussion}

Figure 1 is a typical Zimm plot of AM50F in THF. On the basis of eq 1 , the slopes of $\left[K C / R_{v v}(q)\right]_{C \rightarrow 0} v s q^{2}$ and $\left[K C / R_{v v}(q)\right]_{q \rightarrow 0}$ vs $C$ and the extrapolation of $[K C /$ $\left.R_{v v}(q)\right]_{C \rightarrow 0, q \rightarrow 0}$ respectively led to $\left\langle R_{g}\right\rangle, A_{2}$, and $M_{w}$. The values of $M_{w},\left\langle R_{q}\right\rangle$, and $A_{2}$ for AM50F and AB50F in THF are summarized in Table 1 . Note that $M_{w}$ is only apparent value because AM 50F and AB50F are copolymers, and we should consider the preferential adsorption of the solvent. For comparison, we also listed previously reported gel permeation chromatography (GPC) results. ${ }^{6}$ The negative $A_{2}$ indicates that THF is not a good solvent for either AM50F or BM50F even though it is well-known that THF is a good solvent for both poly(methyl methacrylate) and poly(n-butyl methacrylate) homopolymers. The decrease of the solvent quality must be attributed to the very low solubility of $\mathrm{C}_{60}$ on which the polymer chains were grafted. The higher value of $\mathrm{M}_{\mathrm{w}}$ determined in static LLS indicates the interchain association, a possible micellelike aggregation. 
Table 1. Summary of the LLS Results of $\mathrm{C}_{60}$-Containing Poly(methy methacrylate) and Poly(n-butyl methacrylate) in THFa

\begin{tabular}{|c|c|c|c|c|c|c|c|c|}
\hline \multirow[b]{2}{*}{ sample } & \multicolumn{3}{|c|}{ GPC } & \multicolumn{5}{|c|}{ LLS } \\
\hline & $\mathrm{C}_{60}$, wt $\%$ & $M_{w}, g / m o l$ & $M_{w} / M_{n}$ & $\mathrm{dn} / \mathrm{dC}, \mathrm{mL} / \mathrm{g}$ & $M_{w}, g / m o l$ & $\left\langle\mathrm{R}_{\mathrm{g}}\right\rangle, \mathrm{nm}$ & $\left\langle\mathrm{R}_{\mathrm{h}}\right\rangle, \mathrm{nm}$ & $\left\langle R_{g}\right\rangle /\left\langle R_{h}\right\rangle$ \\
\hline $\begin{array}{l}\text { AM50F } \\
\text { AB50F }\end{array}$ & $\begin{array}{l}8.2 \\
6.8\end{array}$ & $\begin{array}{l}1.1 \times 10^{4} \\
1.2 \times 10^{4}\end{array}$ & $\begin{array}{l}1.4 \\
1.5\end{array}$ & $\begin{array}{l}9.5 \times 10^{-2} \\
8.3 \times 10^{-2}\end{array}$ & $\begin{array}{l}1.6 \times 10^{5} \\
3.3 \times 10^{4}\end{array}$ & $\begin{array}{l}50 \\
50\end{array}$ & $\begin{array}{l}70 \\
70 *\end{array}$ & $\begin{array}{l}0.7 \\
0.7\end{array}$ \\
\hline
\end{tabular}

a Only for the peak related to the interchain aggregates. The relative errors: $M_{w}, \pm 5 \%$; $d n / d C, \pm 2 \% ;\left\langle R_{g}\right\rangle, \pm 10 \%$; and $\left\langle R_{h}\right\rangle, \pm 5 \%$.

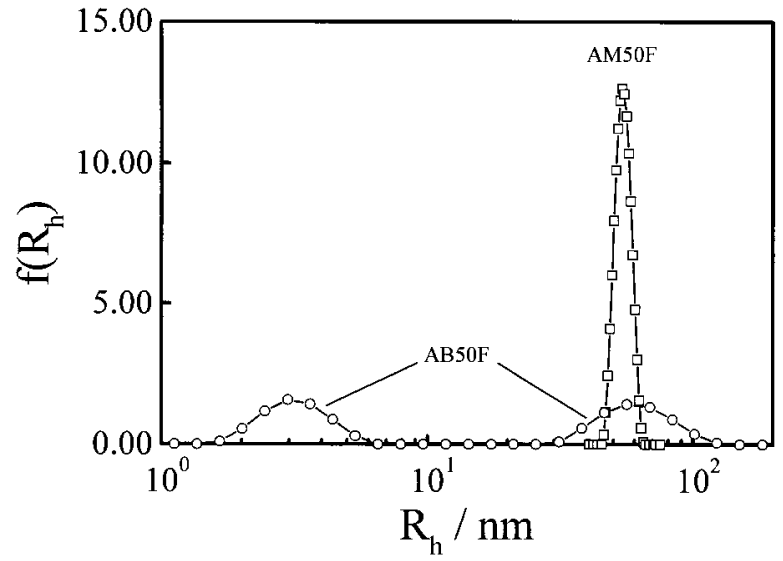

Figure 2. Typical normalized hydrodynamic radius $\left(R_{h}\right)$ distributions of fullerene-containing poly (methyl methacrylate) (AM50F) and poly(n-butyl methacrylate) (AB50F) in THF, where $\mathrm{T}=25{ }^{\circ} \mathrm{C}$ and the polymer concentrations are $4.25 \times$ $10^{-3}$ and $4.04 \times 10^{-3} \mathrm{~g} / \mathrm{mL}$, respectively.

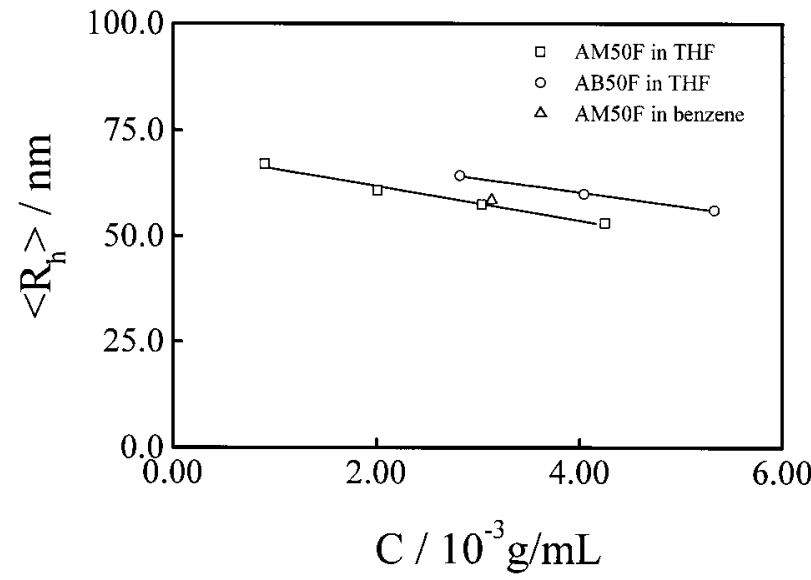

Figure 3. Concentration dependence of the average hydrodynamic radius $\left(\left\langle R_{h}\right\rangle\right)$ of the peak in Figure 2 related to the interchain aggregates of $\mathrm{AM} 50 \mathrm{~F}$ and $\mathrm{AB} 50 \mathrm{~F}$ in $\mathrm{THF}$ and benzene, respectively.

Figure 2 shows typical normalized hydrodynamic radius $\left(R_{h}\right)$ distributions of the fullerene-containing polymers in THF, where the concentration is $\sim 4 \times 10^{-3}$ $\mathrm{g} / \mathrm{mL}$. AM50F in THF has only a single narrowly distributed peak located at $R_{h} \sim 54 \mathrm{~nm}$, while AB50F has two distinct peaks located at $\mathrm{R}_{\mathrm{h}} \sim 3$ and $60 \mathrm{~nm}$. A concentration-dependent study showed that the position of the peak located at $\sim 3 \mathrm{~nm}$ is nearly independent of the polymer concentration. Considering the GPC values of $M_{w}$ listed in Table 1, we can attribute the peak located at $\sim 3 \mathrm{~nm}$ to individual polymer chains and the peak located at $\sim 60 \mathrm{~nm}$ to the interchain association. Note that $f\left(R_{h}\right)$ is an intensity-weighted distribution, and the scattering intensity is proportional to $\mathrm{M}_{\mathrm{w}}{ }^{2}$; i.e., each large interchain aggregate scatters much more light than a single chain. Therefore, the peak located at $\sim 60$ $\mathrm{nm}$ actually represents only a very small number of large interchain aggregates even its area looks large.

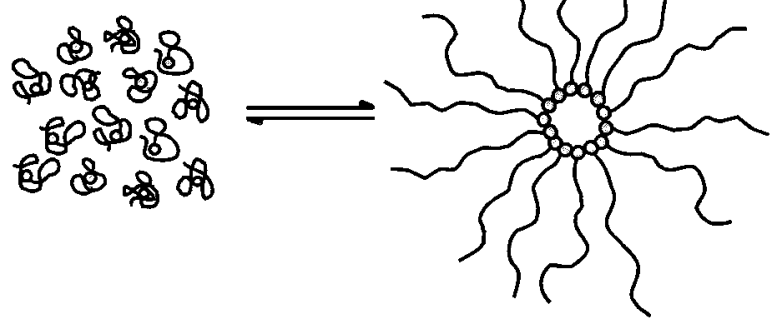

Figure 4. Schemetic of the equilibrium between individual fullerene-containing polymer chains and the micelle-like coreshell interchain aggregate.

Therefore, most of the AB50F chains exist as individual molecules. This is why AB50F in THF has a much lower apparent $\mathrm{M}_{w}$ than AM50F in THF even though their interchain aggregates have a similar size.

Figure 3 shows the concentration dependence of the average hydrodynamic radius $\left(\left\langle R_{h}\right\rangle\right)$ of the peak in $f\left(R_{h}\right)$ related to the interchain aggregates. The negative slope is not expected. For a diffusive relaxation, the line width $\Gamma$ is a function of both $C$ and $q, 12,13$ i.e., $\Gamma / q^{2}=D=D_{0}(1$ $\left.+f\left\langle R_{g}^{2}\right\rangle q^{2}\right)\left(1+k_{d} C\right)$, where $D_{0}$ is the translational diffusion coefficient at $C \rightarrow 0$ and $q \rightarrow 0 ; f$ is a dimensionless constant depending on the chain structure, solvent quality, and polydispersity; and $k_{d}$ is the diffusion second virial coefficient, a difference between the thermodynamic term $\left(2 \mathrm{~A}_{2} \mathrm{M}_{\mathrm{w}}\right)$ and the hydrodynamic term $\left(C_{D}\left\langle R_{h}\right\rangle^{3} / M_{w}\right)$ with $C_{D}$ being a positive constant; namely, $k_{D}=2 A_{2} M_{w}-C_{D}\left\langle R_{h}\right\rangle^{3} / M_{w}$. For a negative $A_{2}, D$ should decrease as $C$ increases, or in the other words, $R_{h}$ should increase as $C$ increases because $\mathrm{R}_{\mathrm{h}} \sim 1 / \mathrm{D}$.

How to explain this apparent contradiction? Table 1 shows that the ratios of $\left\langle\mathrm{R}_{\mathrm{g}}\right\rangle /\left\langle\mathrm{R}_{\mathrm{h}}\right\rangle$ are close to the value (0.78) predicted for a uniform nondraining sphere. Moreover, the scattering angle independence of $\left\langle R_{h}\right\rangle$ also suggests that the interchain aggregates are spherical. On the basis of the micellelike (core-shell) structure schematically shown in Figure 4 and the length (molar mass) of individual chains, we know that the grafted polymer chain must be fully stretched; and on average, each $\mathrm{C}_{60}$ was only grafted one polymer chain. Otherwise, it would be impossible for the interchain aggregates to have such a large $\left\langle R_{h}\right\rangle$. The estimated aggregation number is ca. 14. The chain density $(\rho)$ of the aggregate in its hydrodynamic volume estimated on the basis of $\rho$ $=M_{w} /\left(4 / 3 \pi\left\langle R_{h}\right\rangle^{3} N_{A}\right)$ is as low as $2 \times 10^{-4} \mathrm{~g} / \mathrm{cm}^{3}$. Therefore, the shell made of the stretched polymer chains should be very soft and compressible. Also, the second virial coefficient $\left(A_{2}\right)$ of the shell must be positive, which resulted in a positive $k_{D}$. This is why $\left\langle R_{h}\right\rangle$ decreases as $\mathrm{C}$ increases. This concentration dependence can also be viewed from the following angle. A simple estimate shows that the polymer concentrations were comparable to the overlap concentration $\left(\mathrm{C}^{*}\right)$. As the concentration increases, the compression of the soft shell 
due to the effect of the excluded volume led to a decrease of $\left\langle R_{h}\right\rangle$. Figure 3 also shows that replacing THF with benzene has nearly no effect on $\left\langle R_{h}\right\rangle$ because the $C_{60}$ molecules on the polymer chains are the driving force for the aggregates.

In summary, a combination of static and dynamic LLS results has revealed that, for the $\mathrm{C}_{60}$-containing poly(methyl methacrylate) and poly(n-butyl methacrylate) in THF , there exists an equilibrium between individual polymer chains and the micelle-like core-shell aggregates with $\mathrm{C}_{60}$ as the core and the polymer chains as the shell. AB50F has a longer side chain and contains less $\mathrm{C}_{60}$ so that most of the AB50F molecules in THF exist as individual chains, while for AM50F the equilibrium shifts toward the interchain association, and we only observed the larger aggregates. The larger size and low chain density of the interchain aggregates indicate that the polymer chains made of the shell must be highly stretched.

Acknowledgment. Financial support of this work by RGC (Research Grants Council of the Hong Kong Special Administration Region) Earmarked Grants (1997/ 98 CUHK 4181/97P, 2160082) and the National Distin- guished Young Investigator Fund (1996, A/C No. 29625410) is gratefully acknowledged.

\section{References and Notes}

(1) Diederich, F.; Thilgen, C. Science 1996, 271, 317 and references therein.

(2) Weis, C.; Friedrich, C.; Mulhaupt, R.; Frey, H. Macromolecules 1995, 28, 403.

(3) Sun, Y. P.; Ma, B.; Bunker, C. E.; Liu, B. J . Am. Chem. Soc. 1995, 117, 12705

(4) Okamura, H.; Terauchi, T.; Minoda, M.; Fukuda, T.; Komatsu, K. Macromol ecules 1997, 30, 5279.

(5) Okamura, H.; Ide, N.; Minoda, M.; Komatsu, K.; Fukuda, T. Macromolecules 1998, 31, 1859.

(6) Lu, Z. H.; Goh, S. H.; Lee, S. Y. Polym. Bull. 1997, 39, 661.

(7) Pecora, R. Dynamic Light Scattering, Plenum Press: New York, 1976.

(8) Chu, B. Laser Light Scattering, 2nd ed.; Academic Press: New York, 1991.

(9) Zimm, B. H. J . Chem. Phys. 1948, 16, 1099.

(10) Wu, C.; Xia, K. Q. Rev. Sci. Instrum. 1994, 65, 587.

(11) Provencher, S. W. J . Chem. Phys. 1976, 64, 2772.

(12) Stockmayer, W. H.; Schmidt, M. Pure Appl. Chem. 1982 $54,407$.

(13) Stockmayer, W. H.; Schmidt, M. Macromolecules 1984, 17, 509.

MA981771E 